\title{
A MOBILIZAÇÃO DO CONHECIMENTO PEDAGÓGICO DO CONTEÚDO SOBRE AS LEIS DE NEWTON: ANÁLISE DE UMA SEQUÊNCIA DIDÁTICA PRODUZIDA POR UM RESIDENTE DE CIÊNCIAS DA NATUREZA
}

\author{
THE MOBILIZATION OF PEDAGOGICAL CONTENT KNOWLEDGE ABOUT \\ NEWTON'S LAWS: ANALYSIS OF A DIDACTIC SEQUENCE PRODUCED BY A \\ RESIDENT OF SCIENCES OF NATURE
}

Boniek Venceslau da Cruz Silva ${ }^{1}$

\begin{abstract}
RESUMO: Neste trabalho, compreendemos que a noção de conhecimento pedagógico do conteúdo (Pedagogical Content Knowledge - PCK, em inglês) de Shulman $(1986 ; 1987)$ pode servir como ferramenta de interpretação do processo de transformação de conteúdos físicos em conhecimentos ensináveis no ensino fundamental. Em especial, usamos o modelo de PCK de Ciências, proposto por Magnusson, Borko e Krajcik (1999), para compreender como um residente de Ciências da Natureza mobiliza o seu PCK na construção de uma sequência didática sobre as leis de Newton. Como primeiros resultados, encontramos que um forte conhecimento de conhecimentos de currículo e estratégias didáticas do residente foram fatores primordiais desta empreitada. Destacamos, também, que o processo de construção de sequências didáticas afloram algumas deficiências formativas do residente, como, por exemplo, atreladas aos conhecimento de avaliação de seus estudantes. Por fim, sugerimos que, principalmente, os cursos de formação inicial oportunizem momentos para o desenvolvimento do PCK de futuros professores de Ciências e, em especial, que sejam oportunizados mais momentos de pontes entre a teoria e a prática, como o Pibid e a Residência Pedagógica, que são momentos nos quais seus PCK's são mais fortemente desenvolvidos e mobilizados desde a construção de propostas de ensino até sua execução.

Palavras-chave: Residência Pedagógica, Leis de Newton, Sequência Didática, Conhecimento Pedagógico do Conteúdo.
\end{abstract}

ABSTRACT: In this work, we understand that the notion of pedagogical content knowledge of Shulman $(1986 ; 1987)$ can serve as a tool for interpreting the process of transforming physical content into teachable knowledge in elementary school. In particular, we use the PCK model about Science, proposed by Magnusson, Borko and Krajcik (1999), to understand how a Natural Sciences student mobilizes his PCK in the construction of a didactic sequence on Newton's laws. As first results, we show that presence in the resident of a strong knowledge of curriculum knowledge and didactic strategies were key factors in this work. We also show that the process of constructing didactic sequences shows on some formative deficiencies of the resident, such as, for example, linked to the evaluation knowledge of his students. Finally, we suggest that, mainly, the initial science courses provide opportunities for the development of the PCK of future science teachers and, in particular, show building bridges between theory and practice, for example, Pibid and the Pedagogical Residency, that are moments in which your PCK's are most strongly developed and mobilized from the construction of teaching proposals to their execution.

Keywords: Pedagogical Residency, Newton's Laws, didactic sequence, pedagogical content knowledge.

https://orcid.org/0000-0002-1648-2652 - Doutor em Ensino de Ciências e Matemática pela UFRN. Docente na UFPI. Teresina, Piauí e Brasil. Residencial Jardins do Leste, Quadra I, Casa 15, Verde Lar, CEP: 64057-378, Teresina, Piauí, Brasil. E-mail: boniek@ufpi.edu.br 


\section{Introdução}

A Residência Pedagógica (RP) é um programa pensado e implementado pela Coordenação de Aperfeiçoamento de Pessoal de Nível (Capes) que busca aperfeiçoar a formação dos discentes de cursos de licenciatura, por meio do desenvolvimento de projetos no chão da escola, propiciando pontes entre a teoria e prática, a partir de diferentes didáticas e metodologias.

Com essas pontes, criadas pela RP, o passo seguinte a ser elaborado é como entender o pensamento dos residentes quando estão no seu ofício. Neste trabalho, embora compreendamos que existe um vasto campo de estudos que buscam o mesmo objetivo, utilizaremos a noção de conhecimento pedagógico do conteúdo (Pedagogical Content Knowledge, PCK, em inglês) como uma bússola no sentido da compreensão de como professores constroem e mobilizam seus saberes na prática.

O PCK foi proposto por Lee Shulman $(1986 ; 1987)$, por volta da década de 80, do século passado. Para o autor, o PCK diferencia o conhecimento do especialista na disciplina do docente dela. Citando como exemplo, o cientista e o professor de Ciências da Natureza, o segundo possuiria uma base para o ensino, que são específicos do professor da disciplina, constituída de diferentes conhecimentos, como os conhecimentos pedagógicos, do contexto e do conteúdo, geralmente não apresentáveis no primeiro, que é detentor do conhecimento da área de estudo. Para o pesquisador, o PCK é o amálgama entre o conteúdo e a pedagogia, surgindo, principalmente da transformação de conhecimentos do conteúdo, pedagógico e do contexto (SHULMAN, 1986; 1987).

Para Grossman (1990), ele é o resultado da transformação de conhecimentos do contexto, conteúdo e pedagógico. Magnusson, Borko e Krajcik (1999) definem o PCK como a transformação de vários conhecimentos para ensinar, incluindo o conhecimento particular dos tópicos, problemas, como os métodos de ensino podem ser organizados, representados e adaptados para diversos interesses de aprendizagens e como são apresentados para a sua instrução. Embora, após 30 anos da proposição de Shulman, conforme destaca Kind (2009), as pesquisas sobre o PCK são centradas, geralmente, em investigações direcionadas à definição do termo, deixando de lado o aprofundamento em algumas críticas relacionadas à sua natureza.

Neste sentido, Crispim (2016) busca preencher algumas lacunas apresentadas, como, por exemplo, como se dá o desenvolvimento do PCK de professores na formação inicial. A pesquisadora investigou como ocorre o desenvolvimento do PCK de futuros professores de Química durante o processo de construção de sequências didáticas. Tomando como base a proposta da investigadora, neste trabalho, buscamos compreender como se mobiliza o PCK, referente às leis de Newton, de um residente do curso de licenciatura em Ciências da Natureza, ao construir uma sequência didática, pensada no âmbito da RP, em uma escola pública de Teresina. 


\section{0 conhecimento pedagógico do conteúdo de professores de Ciências da Natureza: o modelo de Magnusson, Borko e Krajcik (1999)}

Embora Shulman defina o que é o PCK, nos seus trabalhos ele não propõe um modelo de PCK para Ciências da Natureza. Esta tarefa ficou na incumbência dos trabalhos posteriores ao seu, citando, apenas alguns, Magnusson, Borko e Krajcik (1999), Park e Oliver (2008), Silva (2018) e Silva e Martins (2018). Neste trabalho, apresentaremos e utilizaremos, como lente para análise da sequência didática, a proposta do primeiro.

Magnusson, Borko e Krajcik (1999) definem o PCK como a transformação de vários conhecimentos para ensinar, incluindo o conhecimento particular dos tópicos, problemas, como os métodos de ensino podem ser organizados, representados e adaptados para diversos interesses de aprendizagens e como são apresentados para a sua instrução.

Para eles, o entendimento do PCK e sua influência na prática docente são necessários para o ensino de Ciências e para a formação de professores de Ciências. Eles se aproximam da definição de Shulman (1986; 1987), quando argumentam que o PCK é entendido como a transformação de vários conhecimentos para ensinar. Essa ideia é exposta no modelo proposto, como pode ser visto na figura 1.

Figura 1 - O modelo de PCK de Magnusson, Krajcik e Borko (1999) (Fonte: Fernandez

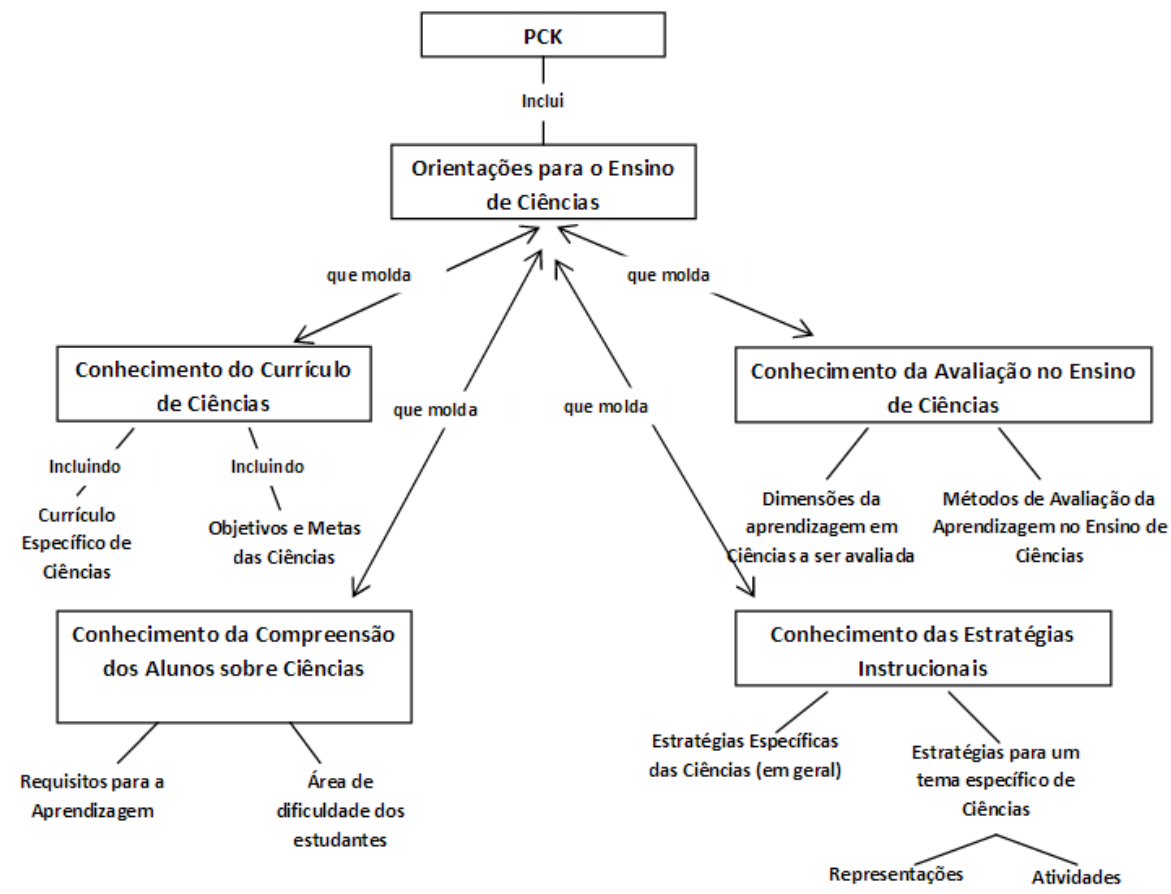

Conforme destaca Fernandez (2015), o modelo de Magnusson, Krajcik e Borko (1999) seguiu a proposta já idealizada por Grossman (1990), incluindo como novo componente do PCK, o conhecimento da avaliação.

Para os autores o PCK inclui uma série de Orientações para o ensino, a qual é responsável por moldar a construção dos conhecimentos que fazem parte do processo de transformação do ensino. 
Para eles, as orientações representam um caminho geral de conceitualização do ensino de Ciências. São geralmente organizadas de acordo com a ênfase da instrução.

Além das Orientações para o ensino de Ciências, Magnusson, Krajcik e Borko (1999) indicam que o PCK inclui mais quatro componentes, a saber: conhecimento do currículo de Ciências, conhecimento da avaliação no ensino de Ciências, conhecimento da compreensão dos alunos sobre Ciências e conhecimento das estratégias instrucionais. No quadro 1, fazemos uma síntese da explicação destes quatro componentes do PCK dos autores.

Quadro 1 - Conhecimentos que compõem o PCK de Magnusson, Krajcik e Borko (1999)

\begin{tabular}{|c|c|}
\hline COMPONENTE & DESCRIÇÃO \\
\hline $\begin{array}{l}\text { CONHECIMENTO DO CURRÍCULO } \\
\text { DE CIÊNCIAS }\end{array}$ & $\begin{array}{l}\text { Este componente consiste em duas categorias } \\
\text { (currículo específico de Ciências e objetos e metas das } \\
\text { Ciências). Inclui os conhecimentos dos professores sobre } \\
\text { metas e objetivos dos alunos nos conteúdos lecionados e } \\
\text { de programas e materiais que são relevantes para ensinar } \\
\text { um domínio específico da Ciência. }\end{array}$ \\
\hline $\begin{array}{l}\quad \text { CONHECIMENTO } \\
\text { COMPREENSÃO DOS ALUNOS SOBRE } \\
\text { CIÊNCIAS }\end{array}$ & $\begin{array}{l}\text { Este componente consiste em duas categorias } \\
\text { (requisitos para a aprendizagem e área de dificuldade dos } \\
\text { estudantes). Inclui os conhecimentos que os professores } \\
\text { devem possuir sobre os estudantes, em especial, como } \\
\text { ajudá-los a desenvolver conhecimentos em conteúdos } \\
\text { específicos da Ciência e de tópicos que os estudantes } \\
\text { apresentam dificuldades para aprender. }\end{array}$ \\
\hline $\begin{array}{l}\text { CONHECIMENTO DA AVALIAÇÃO } \\
\text { NO ENSINO DE CIÊNCIAS }\end{array}$ & $\begin{array}{l}\text { Este componente consiste em duas categorias } \\
\text { (dimensões da aprendizagem em Ciências a ser avaliada e } \\
\text { métodos de avaliação da aprendizagem no ensino de } \\
\text { Ciências). Inclui os conhecimentos da aprendizagem dos } \\
\text { alunos que são importantes avaliar dentro de uma unidade } \\
\text { de estudo e também caminhos para avaliar aspectos da } \\
\text { aprendizagem dos estudantes relacionadas aos tópicos } \\
\text { particulares da unidade. }\end{array}$ \\
\hline $\begin{array}{c}\text { CONHECIMENTO } \\
\text { ESTRATÉGIAS INSTRUCIONAIS }\end{array}$ & $\begin{array}{l}\text { Este componente consiste em duas categorias } \\
\text { (estratégias específicas das Ciências e estratégias para um } \\
\text { tema específico das Ciências). Inclui tanto os } \\
\text { conhecimentos de métodos gerais e esquemas para } \\
\text { proporcionar a instrução nas Ciências como de estratégias } \\
\text { específicas que usualmente colaboram na compreensão de } \\
\text { conceitos específicos. }\end{array}$ \\
\hline
\end{tabular}

Fonte: Magnusson, Krajcik e Borko (1999); tradução nossa.

No próximo tópico, apresentamos o desenho metodológico do nosso trabalho. 


\section{Desenho do estudo: participante, objetivo e processo de análise da sequência didática}

O trabalho foi desenvolvido com um residente do curso de licenciatura em Ciências da Natureza, da Universidade Federal do Piauí (UFPI). Ele frequentava o penúltimo semestre do curso, já tinha concluído as disciplinas que discutem o conteúdo de leis de Newton e, também, disciplinas de cunho didático-pedagógico de sua matriz curricular, o que, supostamente, dotavao de conteúdos relacionados aos processos de construção, análise e avaliação de estratégias didáticas, relacionados ao conceito físico das Leis de Newton.

Dessa forma, com base no modelo de PCK de Ciências, proposto por Magnusson, Krajcik e Borko (1999), buscamos indícios da mobilização do PCK do residente de Ciências da Natureza, relacionado ao conteúdo de Leis de Newton, quando, o mesmo, se propõe a elaborar uma sequência didática (SD) para aplicação em uma escola pública, do município de Teresina, Piauí.

Para analisar a sequência didática, utilizaremos a técnica de análise do conteúdo, de Bardin (2009). Como categorias, tomamos os componentes do modelo de PCK de Ciências de Magnusson, Krajcik e Borko (1999).

\section{0 processo de análise da sequência didática: indícios da mobilização do PCK de um residente de Ciências da Natureza}

Acreditamos que compreender os conhecimentos que influenciam no processo de produção da sequência didática do participante potencializa entender a mobilização do seu próprio PCK (SILVA, 2018). Nossa análise será feita, como dito acima, com base no modelo PCK de Magnusson, Krajcik e Borko (1999). Segue:

\section{Conhecimento do Currículo de Ciências}

Inclui os conhecimentos dos professores sobre metas e objetivos dos alunos nos conteúdos lecionados e de programas e materiais que são relevantes para ensinar um domínio específico da Ciência.

Para essa análise, iremos pegar um enxerto da SD, na qual o residente apresenta os objetivos da sua proposta.

Figura 2 - Objetivos da sequência didática (Fonte: SD do Residente de Ciências da Natureza)

\begin{tabular}{|c|}
\hline Unidade didática: AS LEIS DE NEWTON \\
\hline Pergunta problema: 9 . É possivel diferenciar a ciência de outras formas de conhecimento? Que características são relevantes para isso? \\
\hline Objetivos específicos: \\
$\checkmark$ Compreender as relações de um conhecimento especifico de ciências com outras formas de conhecimento \\
$\checkmark$ Explicar como se deu as 3 leis de newton co-relacionar com outros conhecimentos \\
$\checkmark$ Verificar se as leis de newton modificou a história das ciências e outras formas de conhecimento.
\end{tabular}

Com base na SD, podemos perceber que o residente tenta relacionar o estudo das Leis de Newton com um contexto histórico da mesma, supostamente buscando mostrar aos seus 
estudantes que na produção do conhecimento, a Ciência é influencia e influencia outros campos do conhecimento.

Este fato pode mostrar que o residente conhece documentos referentes ao ensino de Ciências, como por exemplo, os Parâmetros Curriculares Nacionais (PCN) que já contemplam a perspectiva de inserção da História da Ciência no ensino de ciências, apontando, ainda, a contextualização sociocultural do conhecimento como um dos eixos de competências a serem desenvolvidas pelos estudantes (BRASIL, 2002).

Assim, espera-se que os seus estudantes discutam de onde veio as ideias relacionadas às Leis de Newton, como ela evoluiu até chegar onde está, buscando que seus alunos atentem e construam argumentos com bases históricas sobre o conceito físico estudado.

\section{Conhecimento da compreensão dos alunos sobre Ciências}

Inclui os conhecimentos que os professores devem possuir sobre os estudantes, em especial, como ajudá-los a desenvolver conhecimentos em conteúdos específicos da Ciência e de tópicos que os estudantes apresentam dificuldades para aprender. Envolve a compreensão de concepções alternativas de diferentes conteúdos da Ciência e formas de trabalhar-lho com seus estudantes.

Para analisarmos a compreensão sobre esse componente, pegamos o enxerto na SD, que pode ser visto na figura 3.

Figura 3 - Enxerto do desenvolvimento metodológico da SD (Fonte: SD do Residente de Ciências da Natureza)

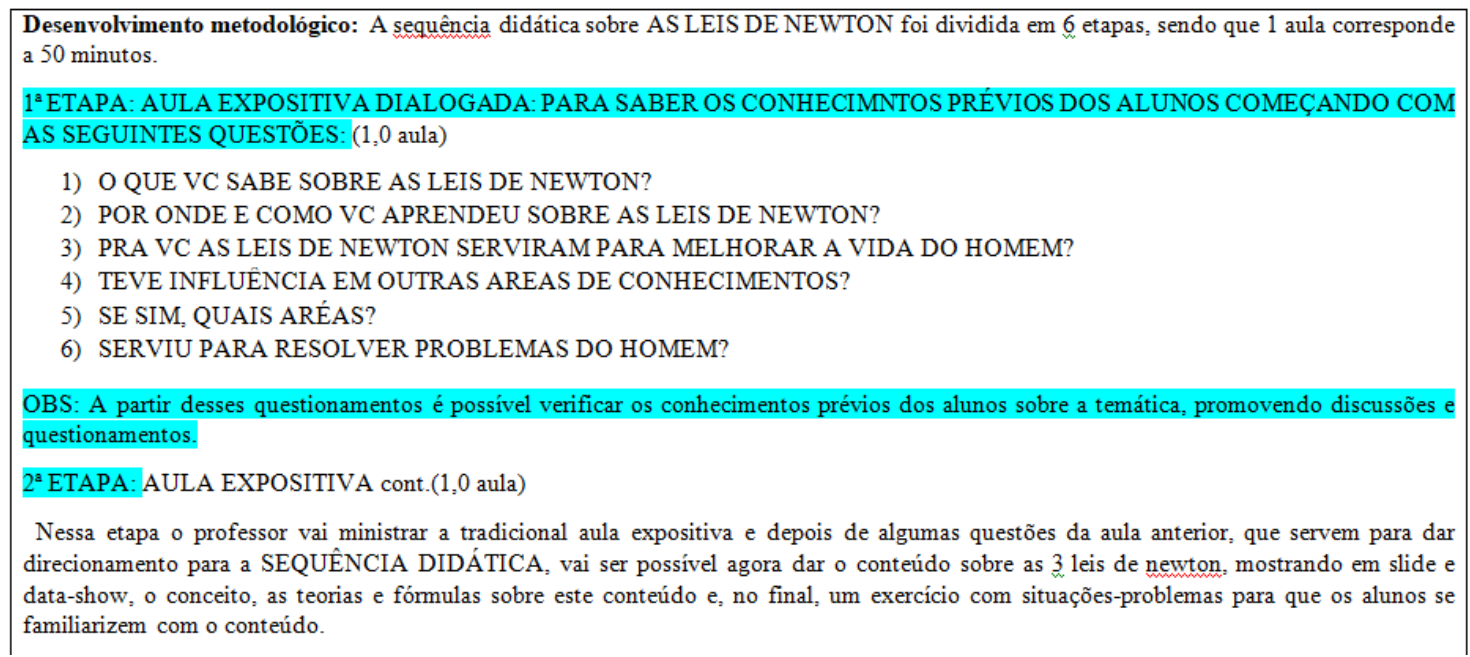

residente apresenta a preocupação de conhecer as concepções dos alunos sobre os conteúdos a ser ministrado, o que mostra ele busca requisitos para a aprendizagem (a presença de concepções alternativas) e possíveis áreas de dificuldade de compreensão dos estudantes sobre os conteúdos e objetivos que ele descreve dentro de sua SD. Assim, podemos notar que ele mobiliza conhecimentos deste componente do seu PCK, em um grau bastante satisfatório.

\section{Conhecimento da avaliação no ensino de Ciências}

Inclui os conhecimentos da aprendizagem dos alunos que são importantes avaliar dentro de uma unidade de estudo e também caminhos para avaliar aspectos da aprendizagem dos 
estudantes relacionadas aos tópicos particulares da unidade. Como demonstra Silva (2018) e Silva e Martins (2018), geralmente, são os conhecimentos menos desenvolvidos dentro do PCK de professores, sejam em formação ou em exercício. Abaixo, apresentamos enxertos de como o residente mobiliza esse componente do PCK dentro da sua SD.

Figura 4 - Critérios de avaliação na SD em diferentes momentos (grifo nosso) - (Fonte: SD do Residente de Ciências da Natureza)

2 2 ETAPA: AULA EXPOSITIVA cont.(1,0 aula)

Nessa etapa o professor vai ministrar a tradicional aula expositiva e depois de algumas questões da aula anterior, que servem para dar direcionamento para a SEQUÊNCIA DIDÁTICA, vai ser possível agora dar o conteúdo sobre as 3 leis de newton, mostrando em slide e data-show, o conceito, as teorias e fórmulas sobre este conteúdo e, no final, um exercício com situações-problemas para que os alunos se familiarizem com o conteúdo.

Avaliação: A avaliação serão os questionários e as perguntas de cada etapa, depois serão avaliados as concepções de cada aluno em relação ao presente conteúdo.

4 ETAPA: RESUMO SOBRE O QUE JÁ APRENDEU (1,5 AULA)

Nessa aula os alunos produzirão um pequeno texto sobre o que eles entenderam sobre as LEIS DE NEWTON, co-relacionando com outras áreas, e farão a leitura do mesmo. Ao final dessa aula, será proposto aos alunos que levem na próxima aula revistas com notícias, gráficos e imagens relacionadas a problemas do homem na sociedade contendo aspectos das 3 leis de Newton e outras áreas de conhecimento.

Depois os alunos vão criar um cartaz e expor para o restante da turma, explicando o porquê dessa escolha e como isso vai ajudar o homem a enfrentar os problemas vivenciados pelas varias áreas do conhecimento não só das ciências.

Analisando a figura 4, notamos que o residente propõe-se a fazer uma avaliação aula por aula, conforme foi feito na segunda etapa. Contudo, na quarta etapa podemos notar a dificuldade do residente em propor uma avaliação para diferentes metodologias de ensino. Podemos inferir que este fato ocorra devido o componente, relacionado ao campo da avaliação, do PCK de Leis de Newton, possivelmente, na sua formação e nas experiências de formativas do mesmo, não foi bem estruturado. Esse problema denota desde a falta de exemplos de como avaliar diferentes metodologias de ensino, como também experiências formativas na sua graduação, desequilibrando o seu PCK, especialmente no que diz respeito às avaliações de seus alunos.

\section{Conhecimento das estratégias instrucionais}

Inclui tanto os conhecimentos de métodos gerais e esquemas para proporcionar a instrução nas Ciências como de estratégias específicas que usualmente colaboram na compreensão de conceitos específicos.

Silva (2018) já sinaliza, em sua pesquisa de doutorado, componentes ligados aos conhecimentos de estratégias instrucionais, no geral, são os que se apresentam bem estruturados nos professores em formação, principalmente naqueles que podem participar de programas de iniciação científica. Na sua investigação, o pesquisador notou que futuros professores de Física, os quais participavam ou participaram do Programa Institucional de Bolsas de Iniciação à Docência (Pibid), conseguiam desenvolver estratégias didáticas mais estruturadas, ao comparar com estudantes que não tiveram as mesmas experiências.

Este fato é notado na SD do residente, na qual ele apresenta uma pluralidade de estratégias didáticas na construção de sua SD, o que para Crispim (2016) é característico de uma boa SD para o ensino de Ciências, devido o fato de alcançar diferentes alunos com diferentes interesses, como podemos notas na figura 5. 
Figura 5 - Recursos didáticos da SD e recorte do texto paradidático (Fonte: SD do Residente de Ciências da Natureza)

Recursos Didáticos: DATASHOW, QUADRO BRANCO, PINCEL PARA QUADRO BRANCO, REVISTAS, TEXTO PARADIDÁTICO E PAPEL CARTÃO.

6ª ETAPA: (2,5 AULAS)
Nesta etapa o professor irá expor um texto didático (APLICAÇÕES DAS LEIS DE NEWTON NO COTIDIANO) para a turma sobre as leis de Newton,
Em seguida, a turma será dividida em 4 grupos com a proposta de reler o texto didático e responder algumas perguntas propostas pelo
professor. Depois de respondido as perguntas, os grupos vão contextualizar o texto com o cotidiano, mostrando a relação com outras áreas do
conhecimento.
TEXTO DIDÁTICO
CONTEÚDO: SITUAÇÕES QUE ENGLOBAM AS 3 LEIS DE NEWTON
TITULO: APLICAÇÕES DAS LEIS DE NEWTON NO COTIDIANO
AUTOR: RICARDOEUGENIO
CERTO DIA UM GRUPO DE AMIGOS FORAM A PRAIA JOGAR VÔLEI: ANA, PEDRO, MANOEL, GUSTAVO.
NO CAMINHO ELES FORAM DISCUTINDO A AULA DE FISICA DO DIAANTERIOR.
ANA: EI MEUS AMIGOS, A AULA DO PROFESSOR BONIEK FOI OTIMA ONTEM, APRENDEMOS AS LEIS DE
NEWTON.
PEDRO: ISSO AI ANA, NEWTON REVOLUCIONOU A CIÊNCIA MODERNAE ATE HOJE FALAMOSE
ESTUDAMOS ISSO.
MANOEL: AS 3 LEIS DE NEWTON FOI ALGO MAGNIFICO PARAA HISTÓRIA DAS CIÊNCIAS.

Na figura 5, podemos notar uma estratégia didática montada exclusiva para o objetivo da SD, que era apresentar para os alunos que a Ciência sofre influências de outros campos do conhecimento, como foi observado na figura 1.

No próximo tópico, apresentamos uma primeira imagem para o PCK sobre as Leis de Newton, do residente de Ciências da Natureza, mobilizado para a construção de sua SD.

\section{Uma primeira imagem do PCK sobre Leis de Newton de um residente de Ciências da Natureza}

Para a construção da imagem do PCK de Leis do Newton do residente de Ciências da Natureza, tomamos como ponto de partida as discussões contidas no tópico anterior, somadas às questões propostas no CoRe, proposto por Loughran; Mulhall e Berry (2004). A segunda parte, pode ser conferida no quadro abaixo no quadro 2 .

Quadro 1 - CoRe para a imagem do PCK de Leis de Newton do residente de Ciências da Natureza*

\begin{tabular}{|l|l|}
\hline Questões do Core & Interpretação com base na SD do residente \\
\hline $\begin{array}{l}\text { 1. O que você pretende que os } \\
\text { estudantes aprendam sobre essa } \\
\text { ideia? }\end{array}$ & $\begin{array}{l}\text { (Objetivos da SD) Compreender as relações de um } \\
\text { conhecimento específico de Ciências com outras formas de } \\
\text { conhecimento; explicar como as 3 leis de Newton se co- } \\
\text { relacionam com outros conhecimentos e verificar se as leis de } \\
\text { Newton modificaram a História das Ciências e outras formas } \\
\text { de conhecimento. }\end{array}$ \\
\hline $\begin{array}{l}\text { 2. Por que é importante para o } \\
\text { estudante aprender essa ideia? }\end{array}$ & $\begin{array}{l}\text { (Etapa } \mathbf{2} \text { da SD) Nesta etapa vai ser exposto um vídeo sobre as } \\
\text { problemáticas atuais no mundo co-relacionando a ciência e } \\
\text { áreas como a geografia, história, política, religião e outras, } \\
\text { fazendo com que os alunos entendam que não é só a ciência } \\
\text { que resolve tudo, mas precisa de outras áreas para assim } \\
\text { tentar resolver as diversas problemáticas do homem. }\end{array}$ \\
\hline
\end{tabular}




\begin{tabular}{|c|c|}
\hline $\begin{array}{l}\text { 3. O que você sabe a mais sobre essa } \\
\text { ideia? }\end{array}$ & Não é apresentado na SD. \\
\hline $\begin{array}{l}\text { 4. Quais são as dificuldade e } \\
\text { limitações ligadas ao ensino dessa } \\
\text { ideia? }\end{array}$ & Não é apresentado na SD. \\
\hline $\begin{array}{l}\text { 5. Que conhecimento sobre o } \\
\text { pensamento dos estudantes tem } \\
\text { influência no seu ensino sobre essa } \\
\text { ideia? }\end{array}$ & Não é apresentado na SD. \\
\hline $\begin{array}{l}\text { 6. Que outros fatores influenciam no } \\
\text { ensino desta ideia? }\end{array}$ & Não é apresentado na SD. \\
\hline $\begin{array}{l}\text { 7. Que procedimentos/estratégias } \\
\text { você emprega para que os alunos se } \\
\text { comprometam com essa ideia? }\end{array}$ & $\begin{array}{l}\text { (Etapa } 4 \text { da SD) Nessa aula os alunos produzirão um pequeno } \\
\text { texto sobre o que eles entenderam sobre as LEIS DE NEWTON, } \\
\text { co-relacionando com outras áreas, e farão a leitura do mesmo. } \\
\text { Ao final dessa aula, será proposto aos alunos que levem na } \\
\text { próxima aula revistas com notícias, gráficos e imagens } \\
\text { relacionadas a problemas do homem na sociedade contendo } \\
\text { aspectos das } 3 \text { leis de Newton e outras áreas de } \\
\text { conhecimento. Depois, os alunos vão criar um cartaz e expor } \\
\text { para o restante da turma, explicando o porquê dessa escolha } \\
\text { e como isso vai ajudar o homem a enfrentar os problemas } \\
\text { vivenciados pelas varias áreas do conhecimento não só das } \\
\text { ciências. } \\
\text { (Etapa } 5 \text { da SD) Nesta etapa vai ser exposto um vídeo sobre as } \\
\text { problemáticas atuais no mundo co-relacionando a ciência e } \\
\text { áreas como a geografia, história, política, religião e outras, } \\
\text { fazendo com que os alunos entendam que não é só a ciência } \\
\text { que resolve tudo, mas precisa de outras áreas para assim } \\
\text { tentar resolver as diversas problemáticas do homem. Após o } \\
\text { vídeo será proposto aos alunos que se reúnam em grupo e } \\
\text { discutam sobre esta temática, verificando assim se foram } \\
\text { modificados ou acrescentados esses conhecimentos expostos } \\
\text { até o momento. } \\
\text { (Etapa } 6 \text { da SD) Nesta etapa o professor irá expor um texto } \\
\text { didático (APLICAÇÕES DAS LEIS DE NEWTON NO COTIDIANO) } \\
\text { para a turma sobre as leis de Newton, Em seguida, a turma } \\
\text { será dividida em } 4 \text { grupos com a proposta de reler o texto } \\
\text { didático e responder algumas perguntas propostas pelo } \\
\text { professor. Depois de respondido as perguntas, os grupos vão } \\
\text { contextualizar o texto com o cotidiano, mostrando a relação } \\
\text { com outras áreas do conhecimento. }\end{array}$ \\
\hline $\begin{array}{l}\text { 8. Que maneiras específicas você } \\
\text { utiliza para avaliar a compreensão } \\
\text { dos alunos sobre essa ideia? }\end{array}$ & $\begin{array}{l}\text { (Etapa da Avaliação) A avaliação serão os questionários e as } \\
\text { perguntas de cada etapa, depois serão avaliados as } \\
\text { concepções de cada aluno em relação ao presente conteúdo. }\end{array}$ \\
\hline
\end{tabular}

Fonte: $\mathrm{O}$ autor (* Preenchido com base em enxertos da SD produzida pelo residente de Ciências da Natureza).

Com base no tópico anterior e da nossa interpretação da SD, chegamos a primeira imagem do PCK das Leis de Newton, mobilizada durante a produção da estratégia didática. Observe: 
Figura 6 - Imagem do PCK de Leis de Newton do residente de Ciências da Natureza, mobilizada na produção da sequência didática (Fonte: SD do Residente de Ciências da Natureza. Elaborada no CmapTools 6.04)

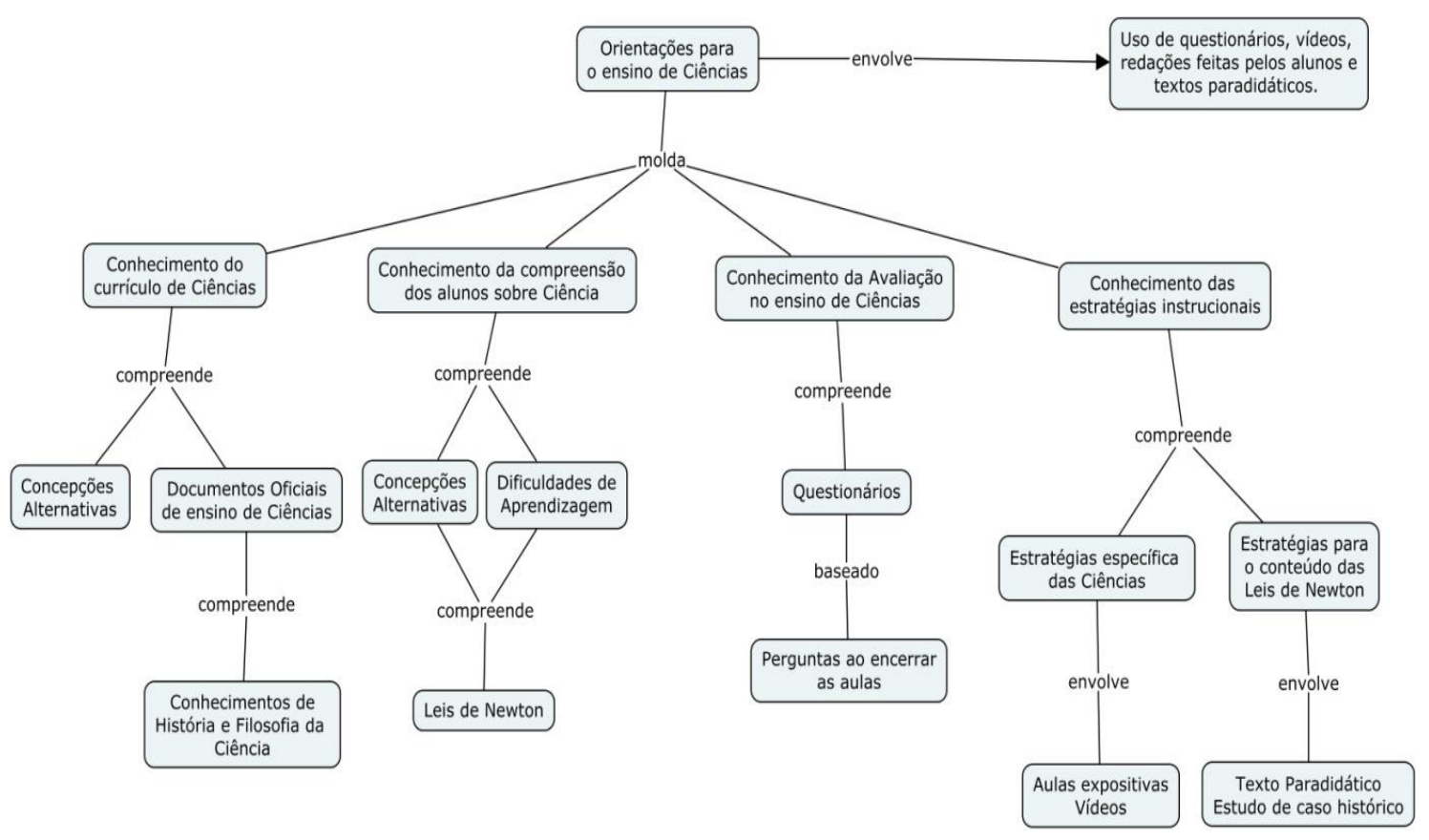

No próximo tópico, tecemos nossas considerações finais.

\section{Considerações finais}

O estudo desenvolvido aponta para alguns conhecimentos que são fundamentais para um melhor desenvolvimento do PCK de futuros professores de Ciências, de forma geral, e, de forma específica para o PCK sobre as leis de Newton. Podemos notar, na nossa investigação, que o processo de construção de sequências didáticas potencializam a melhor construção de conhecimentos relacionados aos currículos e as estratégias didáticas de professores que se propõe a tal tarefa.

Assim, compreendemos que a elaboração de sequências didáticas pode sinalizar elementos que ajudam a entender o desenvolvimento do PCK/NdC dos futuros professores de Física. Na mesma direção, Crispim (2016) argumenta a possibilidade de mobilização de conhecimentos da base, que formam o PCK ainda na formação inicial, durante o processo de construção de sequências didáticas.

Assim, acreditamos que compreender indícios da mobilização do PCK sobre as leis de Newton do residente e uma primeira imagem deste PCK pode-nos dar indícios das fragilidades e potencialidades da formação do futuro professor, possibilitando aos seus formadores intervenções mais direcionadas para as suas necessidades formativas, sejam ainda na sua graduação ou em cursos de formação continuada, ampliando o seu desenvolvimento profissional de forma mais equilibrada. 


\section{Referências}

BARDIN, L. Análise de conteúdo. Lisboa: Edições 70, 2009.

CRISPIM, C. V. O conhecimento pedagógico do conteúdo de licenciando em Química: uma experiência baseada na produção de sequências didáticas. 2016. Dissertação (Mestrado em Educação em Ciências), Universidade Estadual de Santa Cruz, 2016.

FERNANDEZ, C. Revisitando a base de conhecimentos e o conhecimento pedagógico do conteúdo (PCK) de professores de Ciências. Revista Ensaio, v. 17, n. 2, p. 500-528, 2015.

GROSSMAN, P. L. The making of a teacher: teacher knowledge and teacher education. New York: Teachers College Press, 1990.

LOUGHRAN, J; MULHALL, P; BERRY, A. In search of pedagogical content knowledge in science: Developing ways of articulating and documenting professional practice. Journal of research in science teaching, v. 41, n. 4, p. 370-391, 2004.

MAGNUSSON, S.; KRAJCIK, J.; BORKO, H. Nature, sources, and development of pedagogical content knowledge for science teaching. In: Examining pedagogical content knowledge. Springer Netherlands, 1999. p. 95-132.

PARK, S.; OLIVER, S. Revisiting the conceptualization of pedagogical content knowledge (PCK): PCK as a conceptual tool to understand teachers as professionals. Research in Science Education, New York, v. 38, p. 261-284, 2008.

SHULMAN, L. S Those who understand: Knowledge growth in teaching. Educational Researcher, p. 4-14, 1986.

. Knowledge and teaching: Foundations of the new reform. Harvard Education Review, v. 57, n. 1, p. $1-23,1987$.

SILVA, B. V. C. O desenvolvimento do conhecimento pedagógico do conteúdo referente à temática Natureza da Ciência na formação inicial de professores de Física. (2018). Tese. (Doutorado em Ensino de Ciências e Matemática), Universidade Federal do Rio Grande do Norte, 2018.

SILVA, B. V. C.; MARTINS, A. F. P. Uma proposta para avaliação do desenvolvimento do conhecimento pedagógico do conteúdo de futuros professores de Física acerca da temática Natureza da Ciência. Caderno Brasileiro de Ensino de Física, v. 35, n. 2, p. 389-413, 2018. 


\section{Anexos}

\section{Anexo A: Sequência didática do residente*}

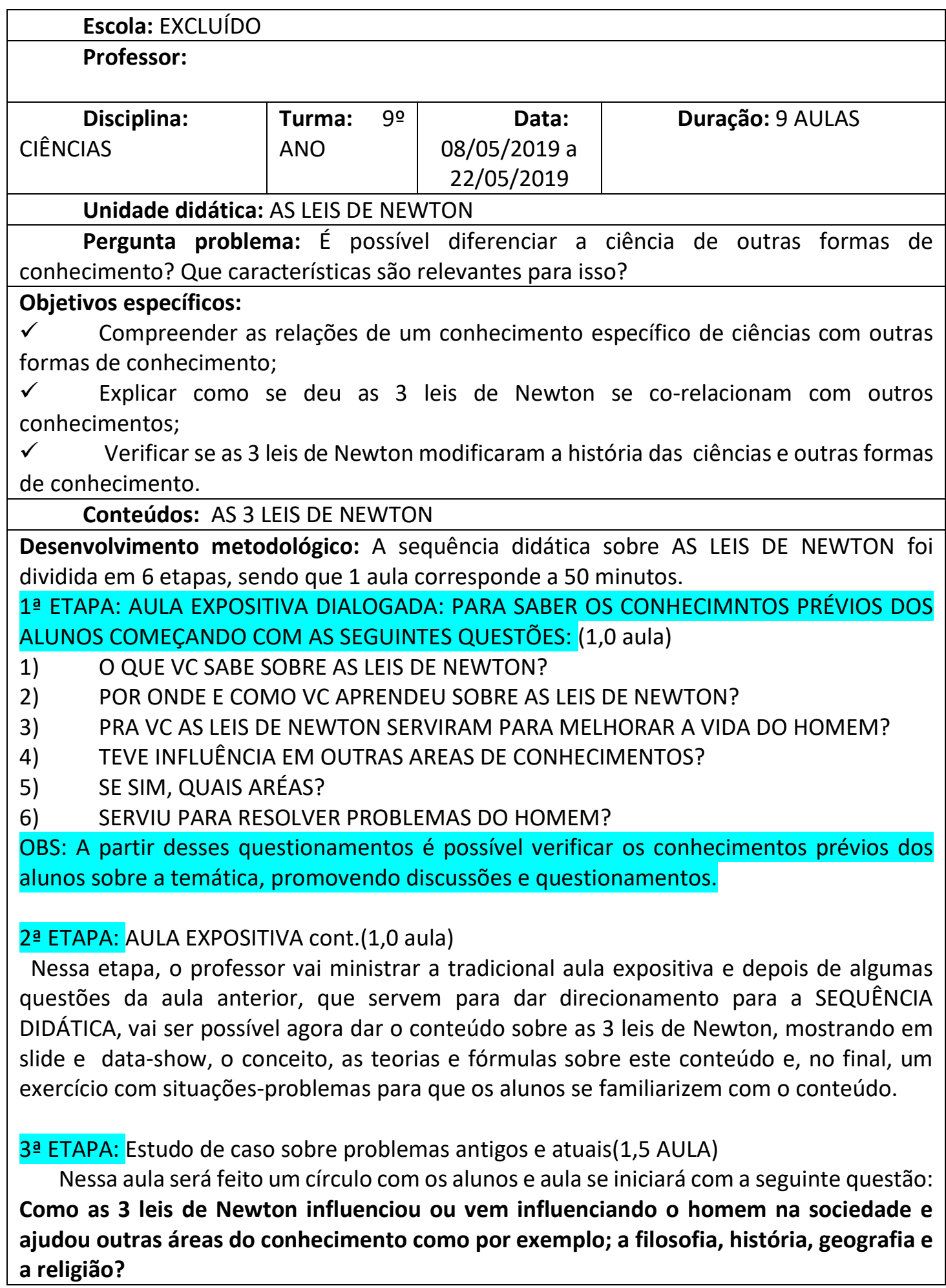


Nesta etapa, o professor vai co-relacionar as teorias de Newton com as vivências do homem, abrangendo não sou as ciências; mas, sim, as outras áreas do conhecimento, colocando assim os alunos como seres crítico e construtores de suas ideias.

\section{4․ ETAPA: RESUMO SOBRE O QUE JÁ APRENDEU (1,5 AULA)}

Nessa aula, os alunos produzirão um pequeno texto sobre o que eles entenderam sobre as LEIS DE NEWTON, co-relacionando com outras áreas e farão a leitura do mesmo para os demais colegas. Ao final dessa aula será proposto aos alunos tragam revistas com notícias, gráficos e imagens relacionadas aos problemas do homem na sociedade, contendo aspectos das 3 leis de Newton e outras áreas do conhecimento.

Depois os alunos vão criar um cartaz e expor para o restante da turma, explicando o porquê dessa escolha e como isso vai ajudar o homem a enfrentar os problemas vivenciados pelas varias áreas do conhecimento e não só das ciências naturais.

5a ETAPA: Vídeo sobre problemas das diversa áreas (1,5 AULA)

Nesta etapa vai ser exposto um vídeo sobre as problemáticas atuais no mundo, corelacionando a ciência e áreas como a geografia, história, política e religião, fazendo com que os alunos entendam que não é só a ciência que resolve tudo, mas precisa de outras áreas para assim tentar resolver as diversas problemáticas do homem.

Após o vídeo será proposto aos alunos que se reúnam em grupo e discutam sobre esta temática, verificando assim se foram modificados ou acrescentados esses conhecimentos expostos até o momento.

\section{6a ETAPA: (2,5 AULAS)}

Nesta etapa, o professor irá expor um texto didático (APLICAÇÕES DAS LEIS DE NEWTON NO COTIDIANO) para a turma, em seguida a turma será dividida em 4 grupos com a proposta de reler o texto didático e responder algumas perguntas propostas pelo professor. Depois de respondido as pergunta, os grupos vão contextualizar o texto com o cotidiano, mostrando a relação com outras áreas do conhecimento.

Recursos Didáticos: DATASHOW, QUADRO BRANCO, PINCEL PARA QUADRO BRANCO, REVISTAS, PINCEL, PAPEL CARTÃO.

\section{Avaliação:}

1. A AVALIAÇÃo SERÁ feitA PElos QUeSTIONÁRIOS E AS PERGUNTAS de CADA ETAPA.

2. DEPOIS SERÁ AVALIADO AS CONCEPÇÕES INICIAIS E FINAIS DE CADA ALUNO EM RELAÇÃO AO CONTEÚDO.

\section{Referências:}

https://www.google.com.br/search?safe=active\&hl=pt-

BR\&tbm=isch\&source $=h p \& b i w=1024 \& b i h=489 \& e i=j 2 I C X e z S H M H C 5 O U P u 8 O h k A I \& q=J O G O$ $+D E+V O L E I S+N A+P R A I A+D E S E N H O \& O q=J O G O+D E+V O L E I S+N A+P R A I A+D E S E N H O \& g s I=i m g$ .3...232.11524..11901...6.0..1.1247.15902.0j1j8j6j4j8j5j1......0....1..gws-wizimg........0.UbL3c_ikVGo\#imgrc=xR3EMAFa3HbdAM: https://beduka.com/blog/materias/fisica/aplicacoes-leis-newton-cotidiano/

* A Sequência didática foi reproduzida na íntegra, contendo, inclusive, possíveis erros de linguagem do residente. 


\section{Anexo B: Texto Paradidático}

\section{TÍTULO: APLICAÇÕES DAS LEIS DE NEWTON NO COTIDIANO}

Certo dia um grupo de amigos foram para a praia jogar vôlei. Eram eles: Ana, Pedro, Manoel e Gustavo.

No caminho, eles foram discutindo sobre a aula de física do dia anterior.

Ana: - Ei meus amigos, a aula do professor Marcos foi ótima ontem. Aprendemos as leis de Newton.

Pedro: - Isso ai, Ana. Newton revolucionou a ciência moderna e até hoje falamos e estudamos isso.

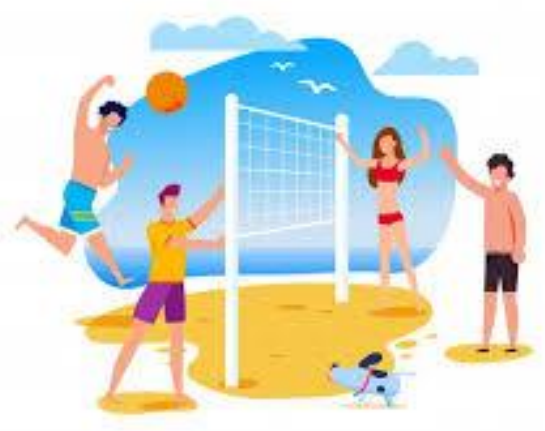

Manoel: - As 3 leis de Newton foram algo magnífico para a história das ciências.

Chegando na praia....

Ana: - Vamos começar o jogo galera!!!

Pedro: - Tive uma ideia pessoal, vamos ver se em nosso jogo tem alguma aplicação das leis de Newton?

Gustavo: - Isso aí, Pedro. Boa ideia.

Ana: - Então, vamos nessa.

Narrador: Manoel vai pro saque.

Narrador: Manoel saca a bola na direção do lado adversário e caí na areia, fazendo assim o primeiro ponto.

Ana: - Galera, vamos ver quais leis de Newton foram aplicadas no movimento da bola?

Pedro: - Já sei galera, foi a segunda lei de Newton. Que diz que o corpo se movimenta e ganha aceleração se for aplicada uma força. Nesse caso, o Manoel aplica uma força na bola e ela ganha aceleração, outra coisa também, nesse caso é uma bola de vôlei, se fosse uma de basquete a aceleração ia diminuir porque a bola de basquete é maior e mais pesada.

Ana: - Muito bem, Pedro. É por isso que você é o nerd da sala. Você sabe tudo, meu garoto. Vou pescar de você na prova. Então, galera, foi aplicada alguma outra lei de Newton ?

Gustavo: - Pelo pouco que sei, acho que sim.

Ana: - Qual, Gustavo?

Gustavo: - Acho que a lei da ação e reação.

Pedro: - Isso, Gustavo. Essa lei diz o seguinte: "para toda ação há sempre uma reação oposta e de igual intensidade. As ações mútuas de dois corpos, um sobre o outro, são sempre iguais e dirigidas em sentidos opostos". Nesse caso, o Manoel aplicou uma força na bola(ação) e a bola aplicou uma força contraria a mão dele de mesma intensidade(reação).

Ana: - Entendi agora. 
Grupo: - Eu também.

Manoel: - Eu também entendi.

Narrador: 0 jogo prosseguiu e terminou $15 \times 12$.

Será que nessa situação cotidiana foi fácil perceber as aplicação de $\mathbf{2}$ das $\mathbf{3}$ leis de Newton? Isso nos remete que alguns conceitos e teorias físicas nos ajudam a explicar as situações do nosso dia-a-dia. 